PACS 73.30.+y, 73.40.-c, 73.50.Fq

\title{
Non-ohmic conduction in tin dioxide based ceramics with copper addition
}

\author{
A.V. Gaponov ${ }^{1}$, A.B. Glot $^{2}$ \\ ${ }^{I}$ Dnipropetrovsk National University, 72, Gagarin Ave., 49010 Dnipropetrovsk, Ukraine \\ E-mail:alexei_gaponov@ukr.net \\ ${ }^{2}$ Universidad Tecnológica de la Mixteca, Carretera a Acatlima km. \\ 2.5, Huajuapan de León, Oaxaca, 69000, México \\ E-mail:alexglot@mixteco.utm.mx
}

\begin{abstract}
The current-voltage characteristics and temperature dependences of electrical conductivity in $\mathrm{SnO}_{2}-\mathrm{Co}_{3} \mathrm{O}_{4}-\mathrm{Nb}_{2} \mathrm{O}_{5}-\mathrm{Cr}_{2} \mathrm{O}_{3}-\mathrm{CuO}$ semiconductor ceramics are studied, and possible mechanism of non-ohmic conduction in these materials is discussed. Due to addition of $\mathrm{CuO}$ up to $0.5 \mathrm{~mol} \%$, the nonlinearity coefficient is increased up to 75 , and the electric field is decreased down to $3900 \mathrm{~V} \cdot \mathrm{cm}^{-1}$ (at $1 \mathrm{~mA} \cdot \mathrm{cm}^{-2}$ ). It makes $\mathrm{CuO}$ addition useful for the preparation of $\mathrm{SnO}_{2}$-based varistors. It is concluded that the electrical conduction is controlled by grain-boundary barriers. The activation energy of electrical conduction $E_{\sigma}$ (the barrier height $\varphi$ ) is decreased with an increase in the electric field $E$. The higher slope of the $E_{\sigma}(E)$ dependence at high fields can be related to a participation of minority carriers (holes). The addition of more than $0.5 \mathrm{~mol} \% \mathrm{CuO}$ leads to degradation of the varistor effect due to percolation via quite conductive $\mathrm{CuO}$ based intergranular phase.
\end{abstract}

Keywords: non-ohmic conduction, grain boundary, varistor, barrier height, tin dioxide ceramics.

Manuscript received 25.01.10; accepted for publication 02.12.10; published online 28.02.11.

\section{Introduction}

Zinc oxide $(\mathrm{ZnO})$ ceramics with certain additives exhibits strong non-ohmic conduction and, therefore, these materials are used for fabrication of varistors transient voltage suppression devices [1,2]. Quite high non-ohmic conduction was also observed in tin dioxide $\left(\mathrm{SnO}_{2}\right)$ based ceramics [3,4]. This observation means that $\mathrm{ZnO}$ ceramics are not unique materials with highly nonlinear current-voltage characteristics. $\mathrm{ZnO}$ varistors exhibit some disadvantages (for example, electrical and thermal degradation) $[2,5,6]$. Therefore, there is a hope that varistors based on tin dioxide could possess better properties $[5,6]$. It was realized that basic electrical behaviour of $\mathrm{SnO}_{2}$ and $\mathrm{ZnO}$ varistors are quite similar, because electrical conduction in these ceramics is controlled by the grain-boundary barriers [3-6].

In recent years, $\mathrm{SnO}_{2}$ ceramics with the varistor effect were rather intensively studied [7-10] mainly from the materials science view-point. However, the mechanism of non-ohmic conduction in $\mathrm{SnO}_{2}$ varistor ceramics is still unclear. It was shown that addition of oxides with a low melting point $\left(\mathrm{Bi}_{2} \mathrm{O}_{3}, \mathrm{~V}_{2} \mathrm{O}_{5}, \mathrm{CuO}\right)$ gives certain improvements in the density and electrical parameters of $\mathrm{SnO}_{2}$ varistor ceramics [11-15]. Probably, addition of copper oxide to $\mathrm{SnO}_{2}-\mathrm{CoO}-\mathrm{Nb}_{2} \mathrm{O}_{5}-\mathrm{Cr}_{2} \mathrm{O}_{3}$ looks quite useful for the achievement of desired parameters of $\mathrm{SnO}_{2}$ varistors $[14,15]$. Thus, in this paper we have studied $\mathrm{SnO}_{2}-\mathrm{CoO}-\mathrm{Nb}_{2} \mathrm{O}_{5}-\mathrm{Cr}_{2} \mathrm{O}_{3}$ ceramics with various amounts of $\mathrm{CuO}$ addition. But there is no information about the conduction mechanism in these materials. Therefore, it would be interesting to study the high-field conduction at various temperatures in recently developed $\mathrm{SnO}_{2}-\mathrm{CoO}-\mathrm{Nb}_{2} \mathrm{O}_{5}-\mathrm{Cr}_{2} \mathrm{O}_{3}-\mathrm{CuO}$ varistor ceramics.

Usually, the current-voltage characteristics of oxide varistors are approximated within the narrow range of current densities by the empiric expression $j=B E^{\beta}$, 
where $j$ is the current density and $E$ is the electric field, $\beta$ is a dimensionless constant (nonlinearity coefficient) and $B$ is a constant with dimension giving the current density $j$ in $\mathrm{A} \cdot \mathrm{cm}^{-2}$, if the electric field $E$ is expressed in $\mathrm{V} \cdot \mathrm{cm}^{-1}$. The nonlinearity coefficient is defined by the expression $\beta=(E / j)(d j / d E)$. Usually the nonlinearity coefficient is estimated at a fixed current density (for example, at $1 \mathrm{~mA} \cdot \mathrm{cm}^{-2}$ ). In this case, it can be denoted as $\beta_{1}$. For the indication of the electric field range where the nonlinearity of $j(E)$ characteristic takes place, the value of the electric field at $1 \mathrm{~mA} \cdot \mathrm{cm}^{-2}\left(E_{1}\right)$ is introduced. The values $\beta_{1}$ and $E_{1}$ are used frequently as the main empiric parameters of a varistor.

However, the empiric $j(E)$ expression and empiric parameter $\beta_{1}$ cannot enable in understanding the mechanism of non-ohmic conduction. Therefore, starting from the assumption that non-ohmic conduction in $\mathrm{ZnO}$ and $\mathrm{SnO}_{2}$ varistor ceramics is attributed to the decrease of the barrier height with electric field, the expression for the current-voltage characteristic was obtained $[12,16,17]$ :

$$
j(E)=\sigma_{0} E \exp (\alpha E),
$$

where $\sigma_{0}$ is the conductivity of material at low electric fields, $\alpha$ is the nonlinearity factor. In the case of thermionic emission across the barrier, the parameter $\alpha$ is proportional to the rate of change in the barrier height $\varphi$ with the electric field $E[12,16,17]$ :

$$
\alpha=\frac{1}{k T}\left(-\frac{d \varphi}{d E}\right),
$$

where $k$ is the Boltzmann constant, $T$ is the absolute temperature.

Therefore, in this paper electrical properties of $\mathrm{SnO}_{2}-\mathrm{CoO}-\mathrm{Nb}_{2} \mathrm{O}_{5}-\mathrm{Cr}_{2} \mathrm{O}_{3}$ ceramics with various amounts of $\mathrm{CuO}$ addition were studied, then current-voltage characteristics of some $\mathrm{SnO}_{2}-\mathrm{CoO}-\mathrm{Nb}_{2} \mathrm{O}_{5}-\mathrm{Cr}_{2} \mathrm{O}_{3}-\mathrm{CuO}$ ceramics at different temperatures were obtained, and the dependences of the activation energy of electrical conduction on the electric field were found from them.

\section{Experimental details}

Ceramics were prepared by the conventional oxide mixture method using distilled water. The compositions were (mol.\%) (99.4-x) $\mathrm{SnO}_{2}, 0.5 \mathrm{Co}_{3} \mathrm{O}_{4}, 0.05 \mathrm{Nb}_{2} \mathrm{O}_{5}$, $0.05 \mathrm{Cr}_{2} \mathrm{O}_{3}, x \mathrm{CuO}, \mathrm{x}=0 ; 0.1 ; 0.5 ; 2 ; 8$ (Table). After wet milling and drying, obtained powder was pressed in tablets $12 \mathrm{~mm}$ in diameter and about $0.7 \mathrm{~mm}$ in thickness under the axial pressure $45 \mathrm{MPa}$. Pressed disks were sintered at $1520 \mathrm{~K}$ in air. The details of preparation are described in $[14,15]$. To determine the grain size, scanning electron microscopy (SEM) was used. The shrinkage $\gamma$ was calculated according to the expression $\gamma=\left(D_{0}-D\right) D_{0}{ }^{-1}$, where $D_{0}$ and $D$ are diameters of a sample before and after sintering, respectively.

Electrical measurements were performed using InGa eutectic electrodes prepared at room temperature (for the study of current-voltage characteristics of the samples with various $\mathrm{CuO}$ amounts at $300 \mathrm{~K}$ ) and $\mathrm{Ag}$ electrodes obtained at $1070 \mathrm{~K}$ (for the measurements at different temperatures). It was found that such a heat treatment at $1070 \mathrm{~K}$ leads to a decrease in nonlinearity of current-voltage characteristics.

Current-voltage characteristics were recorded in air within the temperature range $300-423 \mathrm{~K}$. The relative humidity of ambient air was about $50 \%$ at $300 \mathrm{~K}$. The results were obtained avoiding a self-heating of the samples. The nonlinearity coefficient $\beta_{1}$ and electric field $E_{1}$ were estimated at the current density $10^{-3} \mathrm{~A} \cdot \mathrm{cm}^{-2}$.

Temperature dependence of $\mathrm{dc}$ electrical conductivity $\sigma(T)$ was obtained in the range 300-473 K at heating and cooling the samples in air with a rate close to $1 \mathrm{~K} / \mathrm{min}$. Below about $350 \mathrm{~K}$, conductivity was decreased at heating due to desorption of water molecules $[11,18]$. The activation energy of electrical conduction $E_{\sigma}(0)$ at low electric fields (in ohmic region) was estimated from the high-temperature (350-473 K) part of $\sigma_{0}(T)$ dependence using the equation:

$\sigma_{0}=\sigma_{00} \exp \left(-E_{\sigma}(0) / k T\right)$,

where $\sigma_{00}$ is a constant.

Table. Some parameters of $\mathrm{SnO}_{2}-\mathrm{Co}_{3} \mathrm{O}_{4}-\mathrm{Nb}_{2} \mathrm{O}_{5}-\mathrm{Cr}_{2} \mathrm{O}_{3}-\mathrm{CuO}$ ceramics (electrical parameters were obtained for the samples with In-Ga electrodes).

\begin{tabular}{|l|c|c|c|c|c|}
\hline CuO (mol.\%) & 0 & 0.1 & 0.5 & 2 & 8 \\
\hline Linear shrinkage $\gamma(\%)$ & 9.0 & 9.2 & 11.7 & 11.4 & 9.3 \\
Average grain size $l_{g}(\mu \mathrm{m})$ & 4 & 5 & 8 & 8 & 8 \\
Electrical conductivity $\sigma$ & & & & \\
$\left(\mathrm{Ohm}^{-1} \cdot \mathrm{cm}^{-1}\right)$ & $1.2 \cdot 10^{-12}$ & $3.2 \cdot 10^{-12}$ & $4.8 \cdot 10^{-12}$ & $1.4 \cdot 10^{-10}$ & $5.7 \cdot 10^{-9}$ \\
Activation energy of electrical & 1.2 & 1.0 & 0.94 & 0.65 & 0.34 \\
conduction $E_{\sigma}(\mathrm{eV})$ & & & & 7.6 & 3.1 \\
Nonlinearity coefficient $\beta_{1}$ & 54 & 61 & 75 & 3940 & 14740 \\
Electric field $E_{1}\left(\mathrm{~V} \cdot \mathrm{cm}^{-1}\right)$ & 6280 & 4870 & 3900 & 8540 \\
Normalized nonlinearity coefficient & & & & \\
$\beta_{E}=\beta_{1} / E_{1}\left(\mathrm{~cm} \cdot \mathrm{V}^{-1}\right)$ & $8.6 \cdot 10^{-3}$ & $1.25 \cdot 10^{-3}$ & $1.9 \cdot 10^{-3}$ & $8.9 \cdot 10^{-4}$ & $2.1 \cdot 10^{-4}$ \\
Relative dielectric permittivity $\varepsilon(1 \mathrm{kHz})$ & 114 & 397 & 865 & 130 & 60 \\
\hline
\end{tabular}


The capacitance was measured at the frequency $1 \mathrm{kHz}$ using LCRG meter Tesla BM 591.

\section{Results and discussion}

The current-voltage characteristics of $\mathrm{SnO}_{2}-\mathrm{Co}_{3} \mathrm{O}_{4}$ $\mathrm{Nb}_{2} \mathrm{O}_{5}-\mathrm{Cr}_{2} \mathrm{O}_{3}-\mathrm{CuO}$ ceramics with various $\mathrm{CuO}$ amounts are shown in Fig. 1. Rather strong variation in the lowfield conductivity $\sigma$, nonlinearity coefficient $\beta_{1}$ and electric field $E_{1}$ for the samples with different $\mathrm{CuO}$ additions have been found (Table).

The addition of $\mathrm{CuO}$ in the range $0-0.5 \mathrm{~mol} . \%$ gives some increase in the nonlinearity coefficient (Fig. 1 , curves 1 to 3 ). The highest value $\beta=75$ was found for the sample with $0.5 \mathrm{~mol} \% \mathrm{CuO}$ (Table). This value is higher than that observed by us earlier [14] due to the absence of heat treatment at $1070 \mathrm{~K}$ (due to use of In-Ga eutectic electrodes). Higher amounts of $\mathrm{CuO}$ addition (more than 0.5 mol.\%) cause a strong decrease in the nonlinearity and a rise of the low-field conductivity (Fig. 1, curves 4 to 5).

The reason for an increase in the nonlinearity coefficient on $\mathrm{CuO}$ addition in the range $0-0.5 \mathrm{~mol} \%$ (Fig. 1 and Table) can be due to the formation of higher amount of liquid $\mathrm{CuO}$-phase and related more homogeneous distribution of $\mathrm{Co}_{3} \mathrm{O}_{4}$ and $\mathrm{Cr}_{2} \mathrm{O}_{3}$ impurities throughout a sample. These additives play an important role in the obtaining of $\mathrm{SnO}_{2}$ ceramics with highly nonlinear current-voltage characteristics $[3,6]$.

Within the range 0 to $0.5 \mathrm{~mol} \% \mathrm{CuO}$, the electric field $E_{1}$ (at current density $10^{-3} \mathrm{~A} \cdot \mathrm{cm}^{-2}$ ) is decreased (Fig. 1 , curves 1 to 3 ). It is explained by the grain size growth with the copper oxide content (Table). Observed slight increase in the low-field conductivity in the range $0-0.5 \mathrm{~mol} . \% \mathrm{CuO}$ (Fig. 1, curves 1 to 3 ) is rather due to the grain growth. Such a change is typical for a transition from high-voltage to low-voltage $\mathrm{ZnO}$ varistors.

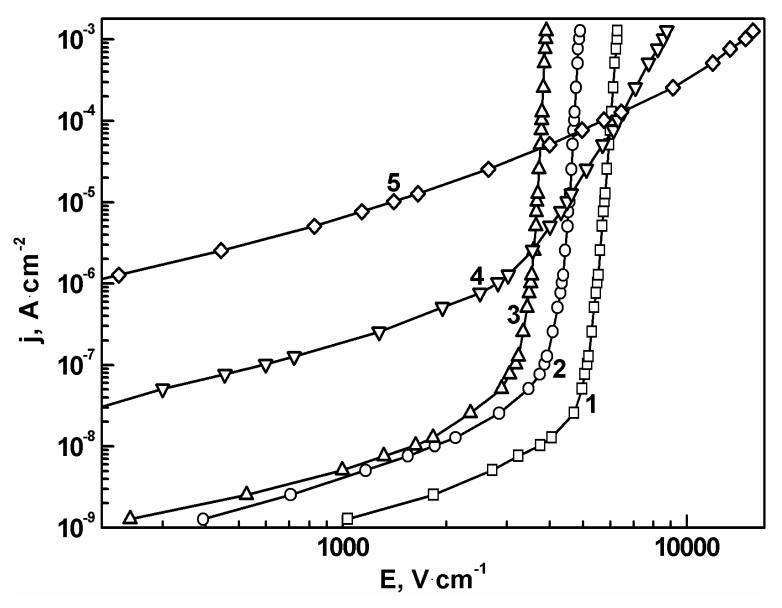

Fig. 1. Current density vs. electric field in $\mathrm{SnO}_{2}-\mathrm{Co}_{3} \mathrm{O}_{4}-\mathrm{Nb}_{2} \mathrm{O}_{5}$ $\mathrm{Cr}_{2} \mathrm{O}_{3}$ varistor ceramics with various amounts of $\mathrm{CuO}$ addition, mol.\%: 0 (1), 0.1 (2), 0.5 (3), 2 (4), 8 (5).
Subsequent decrease in the nonlinearity coefficient with $\mathrm{CuO}$ addition in the range 2-8 mol.\% (Fig. 1 and Table) can be due to percolation across the fairly conductive intergranular $\mathrm{CuO}$ phase covering $\mathrm{SnO}_{2}$ grains and acting as an electrical shunt to the grain boundaries. Similar situation was recently observed in $\mathrm{SnO}_{2}-\mathrm{Co}_{3} \mathrm{O}_{4}-\mathrm{Nb}_{2} \mathrm{O}_{5}-\mathrm{Cr}_{2} \mathrm{O}_{3}-\mathrm{V}_{2} \mathrm{O}_{5}$ varistor ceramics with variation in $\mathrm{V}_{2} \mathrm{O}_{5}$ addition [13].

Temperature dependences of $\mathrm{dc}$ electrical conductivity $\sigma(T)$ for the samples with different $\mathrm{CuO}$ amount have been shown in Fig. 2. With a rise in $\mathrm{CuO}$ addition, the electrical conductivity at a fixed temperature is increased, and the activation energy of electrical conduction $E_{\sigma}$ becomes lower (Table). Below about $350 \mathrm{~K}$, conductivity of ceramics with $\mathrm{CuO}$ addition in the range $0-0.5$ mol.\% (curves $1-3$ in Fig. 2) was affected by humid air (see $[11,13,18]$ ). In the case of low $\mathrm{CuO}$ amounts, humid air can penetrate inside the sample and reach grain-boundary areas. Though at higher values of $\mathrm{CuO}$ additives, $\sigma(T)$ curves are not distorted in the low-temperature part (curves 4 and 5 in Fig. 2) probably because $\mathrm{CuO}$-phase covers $\mathrm{SnO}_{2}$ grains [14] and prevents penetration of humid air to the grainboundary regions.

Electrical conduction in $\mathrm{SnO}_{2}$ ceramics is controlled by the grain-boundary potential barriers [3$16]$. The activation energy of electrical conduction $E_{\sigma}$ is a measure of the barrier height $\varphi\left(\varphi \cong E_{\sigma}\right)$, because using the literature data for single crystals [19] it can be assumed that the Fermi level in the doped $\mathrm{SnO}_{2}$ grain bulk is situated quite close to the conduction band edge. Oxygen vacancies and $\mathrm{Nb}$ impurities can serve as shallow donors in $\mathrm{SnO}_{2}$ [19]. The observed decrease in the low-field barrier height with $\mathrm{CuO}$ addition can be explained by the presence of $\mathrm{CuO}$-phase in the samples [15].

The relative dielectric permittivity $\varepsilon=114$ of $\mathrm{SnO}_{2}$ $\mathrm{Co}_{3} \mathrm{O}_{4}-\mathrm{Nb}_{2} \mathrm{O}_{5}-\mathrm{Cr}_{2} \mathrm{O}_{3}$ ceramics (Table) is quite high due to the existence of thin depletion grain-boundary regions. In the range $0-0.5 \mathrm{~mol} \% \mathrm{CuO}$, the grain size $l_{g}$ is increased, and therefore, $\varepsilon$ of ceramics becomes higher (Table). However, $\mathrm{SnO}_{2}-\mathrm{Co}_{3} \mathrm{O}_{4}-\mathrm{Nb}_{2} \mathrm{O}_{5}-\mathrm{Cr}_{2} \mathrm{O}_{3}-\mathrm{CuO}$ ceramics with 2-8 mol. \% $\mathrm{CuO}$ exhibits lower $\varepsilon$ values (Table) due to the influence of copper oxide phase with not high relative dielectric permittivity about 10 .

As far as the electrical conduction in $\mathrm{SnO}_{2}$ ceramics near room temperature is thermally-activated process with a rather high activation energy [11-14], the thermionic emission across the barrier is the most probable conduction mechanism near $300 \mathrm{~K}$. In this case, the temperature dependence of conductivity $\sigma(T, E)=j(T, E) / E$ in electric field can be written in the form similar to Eq. (3) where $E_{\sigma}(0)$ should be replaced for the activation energy at any electric field $E_{\sigma}(E)$. Then, using Eqs (1) and (2) we have:

$E_{\sigma}(E)=E_{\sigma}(0)-\left(-\frac{d \varphi}{d E}\right) E$. 


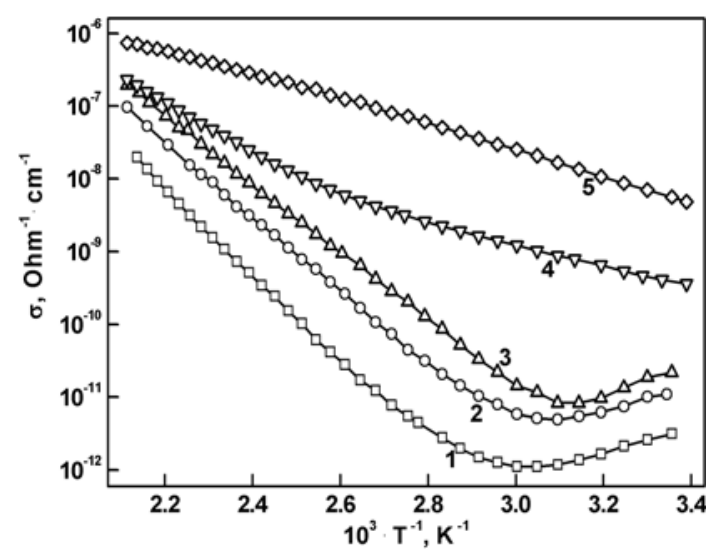

Fig. 2. Temperature dependence of $\mathrm{dc}$ low-field electrical conductivity in air (heating) for $\mathrm{SnO}_{2}-\mathrm{Co}_{3} \mathrm{O}_{4}-\mathrm{Nb}_{2} \mathrm{O}_{5}-\mathrm{Cr}_{2} \mathrm{O}_{3}$ $\mathrm{CuO}$ varistor ceramics with various amounts of $\mathrm{CuO}$ addition, mol.\%: 0 (1), 0.1 (2), 0.5 (3), 2 (4), 8 (5).

The activation energy is linearly decreased with electric field, if the rate of change of the barrier height with electric field is constant. This can be experimentally verified.

In Fig. 3, current-voltage characteristics of studied ceramic material have been presented in the scale $\log (j / E)-E$. Two regions with different non-zero slopes are seen. They are related to the nonlinearity factors $\alpha=\alpha_{1}$ (for mean fields) and $\alpha=\alpha_{2}>\alpha_{1}$ (for the high ones), respectively. The ohmic region with $\alpha=0$ at lowest fields is not revealed. The value $\alpha_{1}$ is related to the increase in conductivity at electric fields that are lower than in the highly nonlinear region. The value $\alpha_{2}$ is related to the highly nonlinear region of currentvoltage characteristic which is empirically described by the nonlinearity coefficient $\beta_{1}$ estimated at $1 \mathrm{~mA} \cdot \mathrm{cm}^{-2}$.

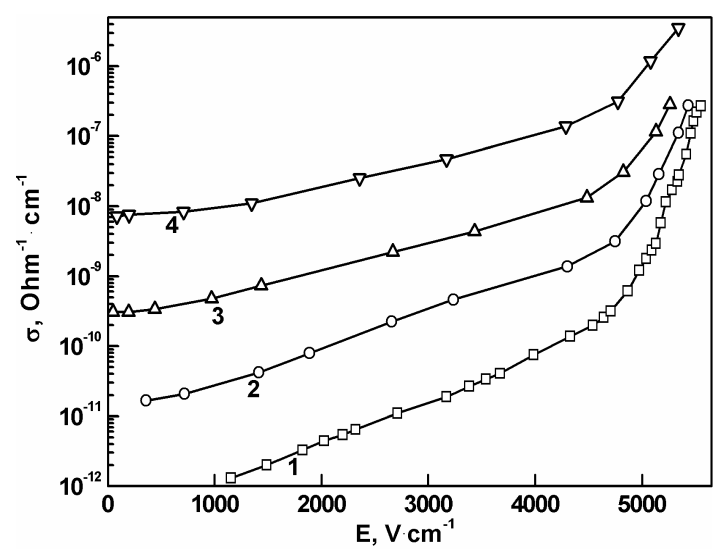

Fig. 3. Dependence of electrical conductivity on electric field for $\mathrm{SnO}_{2}-\mathrm{Co}_{3} \mathrm{O}_{4}-\mathrm{Nb}_{2} \mathrm{O}_{5}-\mathrm{Cr}_{2} \mathrm{O}_{3}-\mathrm{CuO}$ varistor ceramics (with $0.1 \mathrm{~mol} . \% \mathrm{CuO}$ addition) at various temperatures: $304(1)$, 343 (2), 383 (3) and $423 \mathrm{~K}(4)$.
From the family of current-voltage characteristics at various temperatures, the dependences of conductivity $\sigma(T, E)=j(T, E) / E$ at fixed electric fields on temperature were plotted. The activation energy of electrical conduction $E_{\sigma}(E)$ was estimated from the hightemperature part of $\sigma(T)$ dependence (at about $400 \mathrm{~K}$ ) because at this region thermionic conduction mechanism is more probable. The obtained dependence of the activation energy on electric field is presented in Fig. 4 (curve 2). Rather high values of $E_{\sigma}$ in Fig. 4 are in accordance with assumed thermally activated transition of electrons. The slight decrease of the slope inherent to the experimental dependence in the scale $\log \sigma-T^{-1}$ at lower temperatures (in the vicinity of $320 \mathrm{~K}$ ) gives respective displacement of the $E_{\sigma}(E)$ curve to lower values (curve $2^{\prime}$ in Fig. 4). Lower values of the activation energy can be related to the gradual changeover from thermionic emission to thermallyassisted tunnelling. At thermally-assisted tunnelling, electrons cross the barrier at different energies with a maximum at certain energy. This energy probably reflects the activation energy at thermally-assisted tunnelling. Such situation also takes place in $\mathrm{ZnO}$ varistors below about $300 \mathrm{~K}$ [5].

The $j(E)$ characteristics at various temperatures were also obtained for the samples with different amounts of $\mathrm{CuO}$ additives, and the same treatment of experimental data was performed. It is seen that for all the studied samples of $\mathrm{SnO}_{2}$ varistors the barrier height is decreased with electric field (Fig. 4). Earlier, similar behaviour was found for $\mathrm{SnO}_{2}-\mathrm{Co}_{3} \mathrm{O}_{4}-\mathrm{Nb}_{2} \mathrm{O}_{5}-\mathrm{Cr}_{2} \mathrm{O}_{3}$ $\mathrm{Bi}_{2} \mathrm{O}_{3}$ varistor [12].

It is clearly seen that for the sample with the high nonlinearity coefficient $\left(\beta_{1}=61\right), E_{\sigma}(E)$ dependence exhibits a low-field part with low slope and a high-field part with higher slope (Fig. 4, curve 2). Relatively weak decrease of $E_{\sigma}$ at low electric fields in comparison with

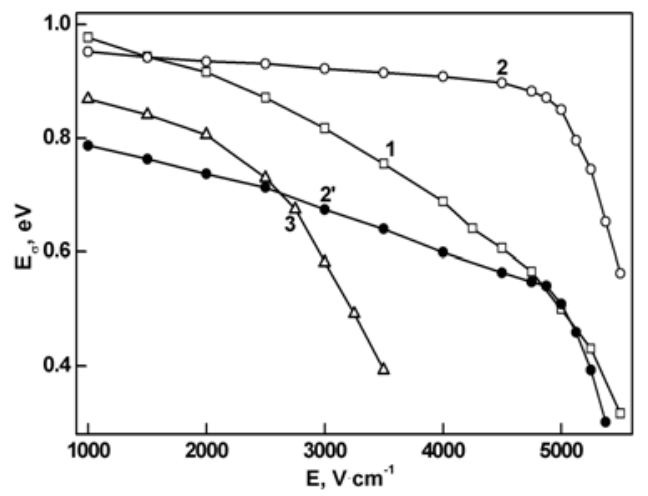

Fig. 4. Field dependence of the activation energy of electrical conduction in $\mathrm{SnO}_{2}-\mathrm{Co}_{3} \mathrm{O}_{4}-\mathrm{Nb}_{2} \mathrm{O}_{5}-\mathrm{Cr}_{2} \mathrm{O}_{3}$ ceramics (curve 1; nonlinearity coefficient $\beta_{1}=54$ ), in $\mathrm{SnO}_{2}-\mathrm{Co}_{3} \mathrm{O}_{4}-\mathrm{Nb}_{2} \mathrm{O}_{5}-\mathrm{Cr}_{2} \mathrm{O}_{3}$ ceramics with $0.1 \mathrm{~mol} . \% \mathrm{CuO}$ (curves 2 and 2'; nonlinearity coefficient $\beta_{1}=61$ ) and with $0.5 \mathrm{~mol} \% \mathrm{CuO}$ (curve 3; nonlinearity coefficient $\beta_{1}=21$ ). The activation energy was estimated at temperatures near $400 \mathrm{~K}$ (curves 1-3) and near $320 \mathrm{~K}$ (curve 2 ). 
the model of grain boundary with fixed interface charge [20] is due to the capture of electrons at the interface. The experimental confirmation of this effect was obtained recently from the isothermal capacitance decay at a voltage bias and subsequent increment of capacitance at zero bias [14].

At high electric fields where high nonlinearity is observed, the activation energy of electrical conduction and the barrier height in $\mathrm{SnO}_{2}$ varistors $(0.3-0.5 \mathrm{eV})$ are still quite high (Fig. 4). This fact means that the conduction process is thermally activated not only at low but also at high electric fields. This makes possible fairly simple explanation of conduction in $\mathrm{SnO}_{2}$ varistors as thermionic emission across the barrier with the barrier height dependent on electric field.

The experimental dependence of the barrier height on the electric field $\varphi(E)$ in $\mathrm{SnO}_{2}$ based varistors consists of two parts: the first one gives a slight decrease in the barrier height at low electric fields, and the second gives a stronger decrease at higher fields. It is necessary to mention that according to the developed approach [12, $16,17]$, the obtained dependence $\varphi(E)$ (Fig. 4, curve 2) reflects a shape of the $\log \sigma$ dependence on the electric field (Fig. 3, curve 1).

It is interesting to note that $\alpha$-values in Fig. 3 are temperature-dependent, because the slopes of curves are gradually decreased with temperature. This fact is related to the thermionic emission of electrons across the grain-boundary barrier (see Eq. (2)).

Probably, a higher slope of the $\varphi(E)$ dependence at high fields in $\mathrm{SnO}_{2}$ varistors is related to a decrease of the negative interface charge on absolute value as a result of impact ionization in reverse biased depletion region or Zener tunnelling from valence to conduction band. It can lead to appearance of minority carriers (holes) in $\mathrm{n}-\mathrm{SnO}_{2}$. As a possible confirmation of hole generation at high fields in $\mathrm{ZnO}$ varistors, the observation of electroluminescence [21,22] and negative capacitance [23] are considered. Earlier the negative capacitance was observed in $\mathrm{SnO}_{2}$ varistors with low nonlinearity [4], and recently we have observed the negative capacitance in $\mathrm{SnO}_{2}-\mathrm{Co}_{3} \mathrm{O}_{4}-\mathrm{Nb}_{2} \mathrm{O}_{5}-\mathrm{Cr}_{2} \mathrm{O}_{3}$ $\mathrm{CuO}$ ceramics with high nonlinearity [24].

\section{Conclusions}

Electrical properties of tin dioxide based $\mathrm{SnO}_{2}-\mathrm{Co}_{3} \mathrm{O}_{4}-$ $\mathrm{Nb}_{2} \mathrm{O}_{5}-\mathrm{Cr}_{2} \mathrm{O}_{3}$ ceramics with $\mathrm{CuO}$ addition in the range $0-8 \mathrm{~mol} . \%$ are studied. The nonlinearity coefficient is increased from 54 to 75 in the range $0-0.5 \mathrm{~mol} . \% \mathrm{CuO}$, and further it is decreased to 3-7 in the range 2-8 mol.\% $\mathrm{CuO}$. The conduction mechanism in ceramics with 0 $0.5 \mathrm{~mol} \% \mathrm{CuO}$ is grain-boundary controlled. The decrease in the barrier height with the voltage is responsible for non-ohmic behaviour. The activation energy of electrical conduction $E_{\sigma}$ in $\mathrm{SnO}_{2}$ varistors as a function of electric field $E$ is obtained experimentally. For the samples with a high nonlinearity coefficient,
$E_{\sigma}(E)$ dependence exhibits the low-field part with low slope and high-field part with higher slope. The highly nonlinear rise of the current density with electric field (the varistor effect) is related to the strong decrease in the activation energy $E_{\sigma}(E)$ (the barrier height). As far as the activation energy is quite high (about $0.3-0.5 \mathrm{eV}$ ) at high electric fields, the conduction process is thermally activated not only at low but also at high electric fields. The higher slope of $E_{\sigma}(E)$ dependence at high fields can be related to a contribution of minority carriers (holes).

\section{References}

1. M. Matsuoka, Nonohmic properties of zinc oxide ceramics // Jpn. J. Appl. Phys. 10(6), p. 736-746 (1971).

2. T.K. Gupta, Application of zinc oxide varistors // J. Amer. Ceram. Soc. 73(7), p. 1817-1840 (1990).

3. A.B. Glot, A.P. Zlobin, The non-ohmic conduction of tin dioxide based ceramics // Inorg. Mater. 25 (2), p. 274-276 (1989).

4. A.B. Glot, Yu.N. Proshkin, A.M. Nadzhafzade, Electrical properties of tin dioxide and zinc oxide ceramics, in: Ceramics Today - Tomorrow's Ceramics, Materials Science Monographs, Ed. P. Vincenzini, vol. 66C, p. 2171-2180. Elsevier, 1991.

5. A.B. Glot, Non-ohmic conduction in oxide ceramics: tin dioxide and zinc oxide varistors, in: Ceramic Materials Research Trends, Ed. P.B. Lin, p. 227-273. Nova Science Publishers, Inc., New York, 2007.

6. P.R. Bueno, J.A. Varela, E. Longo, $\mathrm{SnO}_{2}, \mathrm{ZnO}$ and related polycrystalline compound semiconductors: An overview and review on the voltage-dependent resistance (non-ohmic) feature // J. Eur. Ceram. Soc. 28(3), p. 505-529 (2008).

7. S.A. Pianaro, P.R. Bueno, E. Longo, J.A. Varela, A new $\mathrm{SnO}_{2}$-based varistor system // J. Mater. Sci. Lett. 14(10), p. 692-694 (1995).

8. P.N. Santosh, H.S. Potdar, S.K. Date, Chemical synthesis of a new tin dioxide based $\left(\mathrm{SnO}_{2}\right.$ : $\mathrm{Co}, \mathrm{Al}$, $\mathrm{Nb}$ ) varistor // J. Mater. Res. 12, p. 326-328 (1997).

9. R. Parra, J.E. Rodriguez-Paez, J.A. Varela, M.S. Castro, The influence of the synthesis route on the final properties of $\mathrm{SnO}_{2}$-based varistors // Ceram. Intern. 34, p. 563-571 (2008).

10. R. Metz, D. Koumeir, J. Morel, J. Pansiot, M. Houabes, M. Hassanzadeh, Electrical barriers formation at the grain boundaries of Co-doped $\mathrm{SnO}_{2}$ varistor ceramics // J. Eur. Ceram. Soc. 28, p. 829-835 (2008).

11. I. Skuratovsky, A. Glot, E. Di Bartolomeo, E. Traversa, R. Polini, The effect of humidity on the voltage-current characteristic of $\mathrm{SnO}_{2}$ based ceramic varistor // J. Eur. Ceram. Soc. 24 (9), p. 2597-2604 (2004).

12. A.B. Glot, I.A. Skuratovsky, Non-Ohmic conduction in tin dioxide based varistor ceramics // Mater. Chem. Phys. 99 (2-3), p. 487-493 (2006). 
13. A.V. Gaponov, A.B. Glot, A.I. Ivon, A.M. Chack, G. Jimenez-Santana, Varistor and humiditysensitive properties of $\mathrm{SnO}_{2}-\mathrm{Co}_{3} \mathrm{O}_{4}-\mathrm{Nb}_{2} \mathrm{O}_{5}-\mathrm{Cr}_{2} \mathrm{O}_{3}$ ceramics with $\mathrm{V}_{2} \mathrm{O}_{5}$ addition // Mater. Sci. Eng. B. 145 (1-3), p. 76-84 (2007).

14. A.B. Glot, A.P. Sandoval-Garcia, A.V. Gaponov, R. Bulpett, B.J. Jones, G. Jimenez-Santana, Electronic properties of $\mathrm{SnO}_{2}$-based ceramics with double function of varistor and humidity sensor // $A d v$. in Tech. Mat. and Mat. Proc. J. 10(1), p. 21-32 (2008).

15. A.V. Gaponov, A.B. Glot, Electrical properties of $\mathrm{SnO}_{2}$ based varistor ceramics with $\mathrm{CuO}$ addition // J. Mater. Sci.: Mater. Electron. 21(4), p. 331-337 (2010).

16. A.B. Glot, A simple approach to oxide varistor materials // J. Mater. Sci. 41(17), p. 5709-5711 (2006).

17. A.B. Glot, A model of non-Ohmic conduction in $\mathrm{ZnO}$ varistors // J. Mater. Sci.: Mater. Electron. 17(9), p. 755-765 (2006).

18. I. Skuratovsky, A. Glot, E. Traversa, Modelling of the humidity effect on the barrier height in $\mathrm{SnO}_{2}$ varistors // Mater. Sci. Eng. B 128 (1-3), p. 130-137 (2006).
19. Z.M. Jarzebsky, J.P. Marton, Physical properties of $\mathrm{SnO}_{2}$ materials: III. Optical properties // J. Electrochem. Soc. 123(10), p. 333-346 (1976).

20. W.E. Taylor, N.H. Odell, H.Y. Fan, Grain boundary barriers in germanium // Phys. Rev. B 88, p. 867-875 (1952).

21. A.B. Glot, S.V. Firsin, A.Ya. Yakunin, Fluorescence of ceramics from zinc oxide in an electric field // Izvestiya Vysshikh Uchebnykh Zavedenii. Fizika 24 (5), p. 101-102 (1981), in Russian.

22. G.E. Pike, S.R. Kurtz, P.L. Gourley, H.R. Philipp, L.M. Levinson, Electroluminescence in $\mathrm{ZnO}$ varistors: Evidence for hole contributions to the breakdown mechanism // J. Appl. Phys. 57 (12), p. 5512-5518 (1985).

23. G.E. Pike, Electronic properties of $\mathrm{ZnO}$ varistors: a new model, in: Grain Boundaries in Semiconductors, Eds. G.E. Pike, C.H. Seager, H.J. Leamy, vol. 5, pp. 369-379. Elsevier, 1982.

24. A.B. Glot, A.V. Gaponov, A.P. Sandoval-Garcia, Electrical conduction in $\mathrm{SnO}_{2}$ varistors // Phys. B: Condensed Matter. 405, p. 705-711 (2010). 